\title{
Avaliação das Instituições de Longa Permanência para Idosos do município de Olinda-PE
}

Evaluation of long - term care facilities for the elderly in the municipality of Olinda, state of Pernambuco

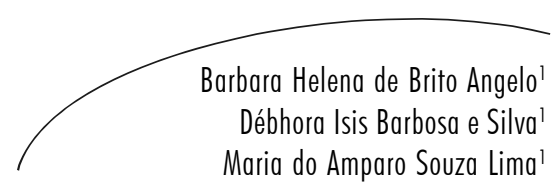

Resumo

Objetivo: Este trabalho se propõe a analisar a organização e funcionamento das instituições de longa permanência para idosos (ILPI) do município de OlindaPE, através da aplicação do instrumento específico da Vigilância Sanitária, elaborado em 2007, verificando se as instituições atendem à normatização do Ministério da Saúde. Materiais e Métodos: Estudo exploratório de abordagem quantitativa, realizado em sete ILPIs particulares, públicas e/ou filantrópicas do município de Olinda-PE. Foram respeitados os aspectos éticos de pesquisa com seres humanos. Os dados foram analisados através do software Excel e apresentados em tabelas e gráficos. Resultados: Há predominância de mulheres sobre homens; $38,4 \%$ possuem grau de dependência I; $33,1 \%$, grau de dependência II; e 28,5\%, grau de dependência III. 100\% das ILPIs têm administrador, $57,1 \%$, serviço médico e de assistência social, $85,7 \%$, serviço de nutrição, $71,4 \%$, técnicos de enfermagem e $42,8 \%$, secretária, psicólogo e enfermeira. Quanto aos serviços que os idosos utilizam em caso de necessidade de atendimento imediato, constatou-se o uso do SUS em $57,1 \%$ das ILPIs; $71,4 \%$ das instituições têm imóvel próprio; $100 \%$ são cadastradas no Conselho Municipal de Idosos; $57,1 \%$ são de natureza filantrópica; $28,6 \%$ são privada e $14,3 \%$, mista. A aposentadoria dos idosos é utilizada em $71,4 \%$ dos casos; $85,7 \%$ das ILPIs apresentam alvará de funcionamento da Vigilância Sanitária. Conclusão: A institucionalização é por vezes a única alternativa para alguns idosos. É necessário que haja uma rede bem articulada de recursos humanos e estruturais para se atender da melhor maneira possível essa população tão peculiar.

Departamento de Ciências da Saúde, Faculdade de Enfermagem N. Sra. das Graças. Universidade de Pernambuco. Recife, PE, Brasil.

Palavras-chave: Idosos. Avaliação. Instituição de Longa Permanência para Idosos. Serviços de Saúde para idosos. 


\section{Abstract}

Objectives:This study aims to examine the organization and operation of longterm care facilities for the elderly in the municipality of Olinda- PE, through a specific Health Surveillance instrument, established in 2007, to assess whether the institutions meet the Ministry of Health regulations. Materials and Methods: Exploratory study of quantitative approach, conducted in seven long-term care facilities for the elderly, public and / or charities of the city of Olinda-PE. Ethical research requirements with human beings were met. Data were analyzed using Excel software and presented in tables and graphs. Results: There is a predominance of women over men, $38.4 \%$ have degree of dependence I, $33.1 \%$ degree of dependence II, and $28.5 \%$ degree of dependency III. $100 \%$ of ILPI have administrator, medical service and $57.1 \%$ of social assistance, $85.7 \%$ service nutrition, $71.4 \%$ technical, nursing and $42.8 \%$ secretary, psychologist and nurse. As the services that older people use in case of need of immediate care, it was the use of SUS in $57.1 \%$ of facilities. $71.4 \%$ of institutions have their own property. $100 \%$ are registered in the City Council for the Elderly, $57.1 \%$ are philanthropic, $28.6 \%$ and $14.3 \%$ are private enterprises. The retirement of the elderly is used in $71.4 \%$ of cases. $85.7 \%$ of institutions have Health Surveillance permission to operate. Conclusion: The institutionalization is sometimes the only alternative for some elderly is a need for a well-articulated network of structural and human resources to meet the best possible way so peculiar that population.
Key words: Elderly. Evaluation. Long Stay Institution for Aged. Health Services for the Aged.

\section{INTRODUÇÃO}

O envelhecimento populacional é uma preocupação emergente na agenda de inúmeros governantes. Ouvimos com frequência que o Brasil não é mais um país jovem. Hoje, temos aproximadamente 11 milhões de pessoas com mais de 60 anos e projeções indicam que seremos o sexto país do mundo em número de idosos no ano de 2020, com aproximadamente 32 milhões de indivíduos na terceira idade. ${ }^{1}$

Sendo um aumento rápido e violento da população idosa, não haverá tempo suficiente para que o país se capacite para lidar de modo adequado com essa população. São previsíveis as situações relacionadas a preconceito, marginalização social, pobreza, abandono, doenças, incapacidades e baixa qualidade de vida. ${ }^{1}$

Várias são as situações em que os idosos são totalmente dependentes, incapazes de realizar as atividades básicas. Nesses casos, se a família exercer atividades no trabalho, a tendência é manter o idoso em uma instituição, mesmo contra sua vontade; ele pode muitas vezes ser enganado quanto ao que representa a instituição a que está sendo encaminhado e da qual poderá nunca mais sair. ${ }^{2}$

Segundo a Portaria ${ }^{\circ}$ 810/89 da Secretaria Nacional de Vigilância Sanitária, consideram-se instituições de longa permanência (ILPI) os estabelecimentos com denominações diversas, correspondentes aos locais equipados para atender pessoas com 60 anos e mais. Sob regime de internato, mediante pagamento ou não, durante um período indeterminado, podem dispor de um quadro de trabalhadores para atender às necessidades de cuidados de saúde, alimentação, higiene, repouso e lazer dos usuários, além de desenvolver outras atividades características da vida institucional. ${ }^{3}$

A institucionalização pode trazer inúmeras consequências, pois toda mudança, por mais simples que seja, implica fatores positivos e negativos. A principal mudança é a adaptação à vida asilar, porque por mais conformado que seja o idoso com a ideia de morar no asilo, ele tem seus passatempos, costumes, afazeres, o papel do avô/avó, pai ou mãe. ${ }^{4} \mathrm{~A}$ família é considerada o habitat natural da pessoa humana. Nela somos mais naturais, mais nós mesmos, conhecidos, pelos 
nossos defeitos e pelas nossas qualidades, sem máscaras sociais. ${ }^{5}$

Em situações em que a institucionalização do idoso é um "mal necessário", é importante considerar que a qualidade dos serviços oferecidos devam ser adequados, para tanto cabe ao Estado realizar seu papel de financiador e fiscalizador dessas atividades, garantindo a esta população os direitos assegurados na legislação em vigor. ${ }^{2}$ As instituições deverão seguir a normatização estabelecida pelo Departamento de Vigilância Sanitária, das Secretarias de Saúde municipais, além de necessitarem de certificado de regularidade, expedido pelo Corpo de Bombeiros. A ILPI deve manter em sua equipe de trabalho profissionais capacitados e com registro nos seus respectivos conselhos de classe, com conhecimento na área de gerontologia e oferecer instalações físicas em condições de habitabilidade, higiene, salubridade e segurança. ${ }^{6}$

Devemos considerar que o processo de envelhecimento leva ao comprometimento da capacidade funcional, determinando limitações para as atividades da vida diária e necessidades específicas, as quais exigem assistência de pessoal qualificado, com conhecimento sobre a senescência e sobre a importância da manutenção e promoção da autonomia e independência nessa faixa etária. ${ }^{7}$

O cidadão idoso deve ser considerado não mais como passivo, mas como agente das ações a eles direcionadas, numa abordagem baseada em direitos, que valorize os aspectos da vida em comunidade, identificando o potencial para o bem-estar físico, social e mental ao longo do curso da vida. ${ }^{8}$ Sabendo-se que a população brasileira vem crescendo e que há um prolongamento da expectativa de vida, é necessário pensar nas peculiaridades desse grupo e nas modificações sociais e institucionais atreladas ao novo perfil da população. Indivíduos idosos totalmente dependentes para as atividades diárias, com dificuldade financeira, vítimas de maus-tratos ou abandono e sem suporte familiar buscam ou são levados a uma instituição asilar. Essa demanda requer uma estruturação desses serviços.
Sob a ótica da adoção de políticas públicas, para se contemplar adequadamente esses "novos velhos”, a questão deve ser estudada e planejada antecipadamente. Este trabalho se propõe a analisar a organização e funcionamento das instituições de longa permanência do município de Olinda-PE, através da aplicação do instrumento específico da Vigilância Sanitária, elaborado em 2007, visando a perceber se as instituições atendem aos requisitos e normatização do Ministério da Saúde. ${ }^{9}$

\section{METODOLOGIA}

Trata-se de uma pesquisa quantitativa, do tipo descritivo-exploratória, na qual se busca observar, registrar, analisar e correlacionar um determinado fenômeno, porém sem manipulá-los. ${ }^{10} \mathrm{O}$ estudo foi realizado em sete instituições de longa permanência para idosos particulares, públicas e/ ou filantrópicas do município de Olinda-PE nos meses de fevereiro e março de 2009.

Para a coleta de dados, utilizou-se o Instrumento de Avaliação para Instituições de Longa Permanência para Idosos da Agência Nacional de Vigilância Sanitária-2007. ${ }^{\circ} \mathrm{O}$ instrumento é subdividido em nove partes, sendo avaliadas questões referentes a clientela, processos operacionais, recursos humanos e infraestrutura física, com ênfase na observância de aspectos essenciais a condições propícias a saúde dos idosos institucionalizados. Os dados foram digitados na planilha do programa Microsoft Excel 2007, e na análise foram distribuídas frequências absolutas e relativas (parâmetros de estatística descritiva), apresentadas em tabelas e gráficos.

Foram respeitados os princípios defendidos pela bioética registrados na Resolução n. 196/96 do Conselho Nacional de Saúde do Ministério da Saúde, ${ }^{11}$ sobre pesquisas envolvendo seres humanos. A pesquisa só foi realizada após aprovação do Comitê de Ética e Pesquisa do Centro Integrado de Saúde Amaury de MedeirosCISAM-UPE sob n084/08, em 23 de dezembro de 2008. Foram preservados todos os dados de identificação pertencentes às ILPIs e nenhum perfil será divulgado. 


\section{RESULTADOS}

O gráfico 1 representa o quantitativo de idosos nas instituições de longa permanência estudadas. Sua observação nos permite concluir que $73,8 \%$ dos idosos institucionalizados são do sexo feminino, enquanto $26,2 \%$ são do sexo masculino.

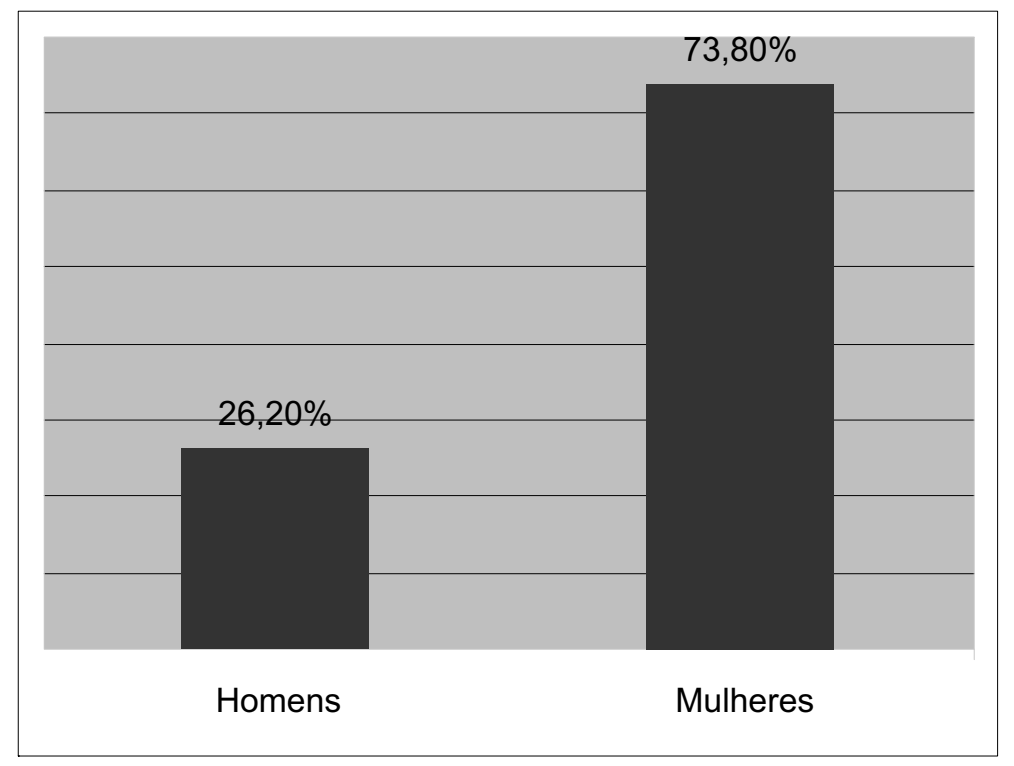

Gráfico 1 - Distribuição dos indivíduos por sexo das instituições de longa permanência para idosos. Olinda, PE, 2009.

$\mathrm{Na}$ tabela 1 encontra-se a distribuição dos idosos segundo o grau de dependência nas instituições pesquisadas. Observa-se que, das sete unidades, seis apresentam uma média de 10 a 30 idosos residentes, e apenas uma possui um quantitativo maior que 60 idosos. Dos 172 indivíduos pesquisados, $38,4 \%$ possuem grau de dependência I; 33,1\% apresentam grau de dependência II; e 28,5\% dos idosos apresentam grau de dependência III.

Tabela1 - Distribuição do número de idosos segundo grau de dependência nas instituições de longa permanência para idosos. Olinda, PE 2009.

\begin{tabular}{|c|c|c|c|c|c|c|c|}
\hline & \multicolumn{2}{|c|}{ Grau de Dependência I } & \multicolumn{2}{|c|}{$\begin{array}{l}\text { Grau de Dependência } \\
\text { II }\end{array}$} & \multicolumn{2}{|c|}{$\begin{array}{l}\text { Grau de Dependência } \\
\text { III }\end{array}$} & \multirow[t]{2}{*}{ TOTAL } \\
\hline & $\mathrm{n}$ & $\%$ & $\mathrm{n}$ & $\%$ & $\mathrm{n}$ & $\%$ & \\
\hline ILPI 1 & 5 & 45,4 & 3 & 27,3 & 3 & 27,3 & 11 \\
\hline ILPI 2 & 1 & 10,0 & 9 & 90,0 & - & 0,0 & 10 \\
\hline ILPI 3 & 24 & 100,0 & - & 0,0 & - & 0,0 & 24 \\
\hline ILPI 4 & 10 & 15,9 & 18 & 28,6 & 35 & 55,5 & 63 \\
\hline ILPI 5 & 7 & 30,4 & 15 & 65,2 & 1 & 4,4 & 23 \\
\hline ILPI 6 & 9 & 36,0 & 10 & 40,0 & 6 & 24,0 & 25 \\
\hline ILPI 7 & 10 & 62,5 & 2 & 12,5 & 4 & 25,0 & 16 \\
\hline TOTAL & 66 & 38,4 & 57 & 33,1 & 49 & 28,5 & 172 \\
\hline
\end{tabular}


A tabela 2 compõe características de funcionamento das ILPIs no que diz respeito à situação do imóvel: $71,4 \%$ das instituições visitadas são próprias e apenas $28,6 \%$ são alugadas. Em relação ao registro no Conselho Municipal de Idosos, 100\% das instituições apresentam-se cadastradas. Nas instituições estudadas, constatamos que $57,1 \%$ são de natureza filantrópica, enquanto $28,6 \%$ são de natureza privada e 14,3\% são de natureza mista. Apenas 14,3\% das instituições recebem auxílio governamental; a aposentadoria dosidosos é utilizada em $71,4 \%$ dos casos e 28,6\% referem não utilizá-la. Apresentam alvará de funcionamento expedido pela Vigilância Sanitária 85,7\% das ILPIs e uma instituição $(14,3 \%)$ está em processo de regulamentação.

Tabela 2 - Distribuição de características de funcionamento das instituições de longa permanência para idosos - Olinda, 2009.

\section{Variáveis}

Situação do Imóvel

Próprio

Alugado

Registro no Conselho Municipal de Idosos

Sim

Não

Natureza Jurídica

Filantrópica

Privada

Mista

Recebe subvenção do governo

Sim

Não

Utiliza aposentadoria do idoso

Sim

Não

Apresenta alvará

Sim

Não n

$\%$

71,4

28,6

$7 \quad 100$

$0 \quad 0$

$4 \quad 57,1$

228,6

$1 \quad 14,3$

$1 \quad 14,3$

$6 \quad 85,7$

$5 \quad 71,4$

28,6

$6 \quad 85,7$

$1 \quad 14,3$
O gráfico 2 apresenta os recursos humanos das instituições pesquisadas: $100 \%$ apresentam administrador, $57,1 \%$ apresentam serviço médico e de assistência social, 85,7\% apresentam o serviço de nutrição, $71,4 \%$ possuem técnicos de enfermagem e 42,8\% têm secretária, psicólogo e enfermeira. 


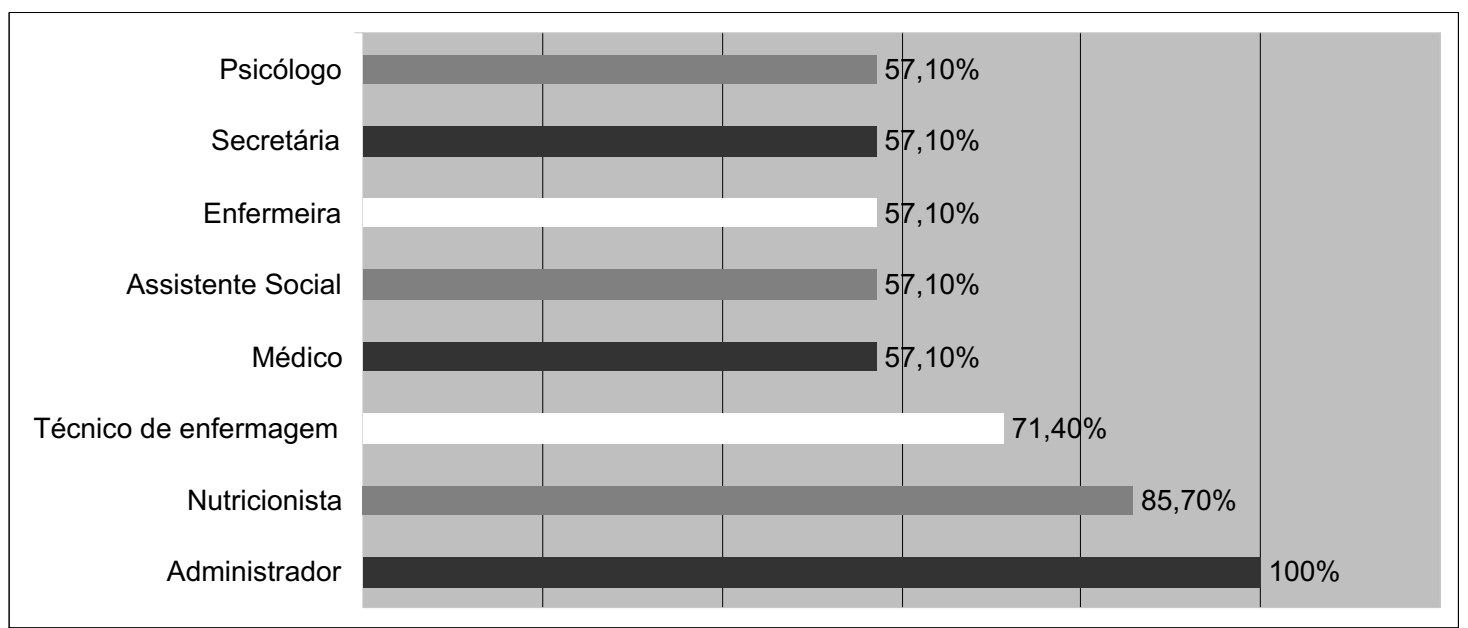

Gráfico 2 - Frequência dos profissionais das instituições de longa permanência para idosos - Olinda, 2009.

*NOTA:1-Os resultados abrangem mais de uma resposta por instituição

A tabela 3 representa a distribuição dos serviços que os idosos utilizam em caso de necessidade de atendimento imediato. Constatou-se o uso do SUS - Pronto-Atendimento 24 horas - em $57,1 \%$ das instituições pesquisadas; as equipes de Saúde da Família, serviços próprios dos locais e planos privados de saúde são referenciados em $14,3 \%$ cada.

Tabela 3 - Distribuição dos serviços requeridos em caso de necessidade de atendimento imediato nas instituições de longa permanência para idosos. Olinda, PE, 2009.

\begin{tabular}{lll}
\hline \multicolumn{1}{c}{ Serviços } & N & $\%$ \\
\hline & & \\
ESF (SUS) & 1 & 14,3 \\
Serviços Paticulares & 1 & 14,3 \\
Serviços da ILPI & 1 & 14,3 \\
Hospital Público & 4 & 57,1 \\
\hline Total & 7 & 100,0 \\
\hline
\end{tabular}

\section{DISCUSSÃO}

O envelhecimento é considerado um processo cumulativo, que se torna irreversível, universal, não-patológico, no qual ocorre deterioração do organismo maduro, podendo incapacitar o indivíduo a desenvolver algumas atividades. A velhice não significa doença e muitas pessoas conservam a saúde até a idade avançada. ${ }^{2}$

O Brasil, a exemplo de outros países, tem valorizado a manutenção dos idosos em seus domicílios, recebendo cuidados de sua família. Esta estratégia, dentre outros objetivos, visa a reduzir custos com assistência hospitalar e instituições asilares. Por outro lado, demanda a disponibilidade de um parente para assistir a necessidade do idoso dependente. ${ }^{12}$

Devido a dependência, abandono e até mesmo por outros fatores, alguns idosos acabam sendo internados em instituições "asilares". ${ }^{2}$ A Portaria n. $810 / 89^{3}$ define idosa a pessoa com 60 ou mais 
anos de idade. Contudo, nas sete instituições pesquisadas, três admitem indivíduos na faixa etária entre 50 a 60 anos com diagnóstico de distúrbios psiquiátricos, o que contradiz a legislação. Observou-se o predomínio dos sujeitos do sexo feminino, correspondendo a $73,84 \%$ do total de residentes, condizente com a realidade nacional observada na literatura e comprovada em estudo realizado em Taubaté-SP, onde $74 \%$ do total de residentes das ILPI são mulheres, fato relacionado à feminização da população idosa em geral. ${ }^{13}$

Em relação ao público-alvo acolhido segundo gênero, verifica-se que a maioria das unidades se enquadra na categoria mista $(57,14 \%)$, ou seja, recebem tanto o idoso do sexo feminino como masculino; $42,86 \%$ das unidades destinam-se apenas ao ingresso de mulheres e não há unidade exclusiva para o sexo masculino. Dados similares foram encontrados em 2006 por Leal et al., em pesquisa realizada na Cidade do Recife-PE, onde $32 \%$ das ILPIs destinam-se ao público feminino e $64 \%$ ao público misto. ${ }^{14}$ No que diz respeito ao número de vagas disponíveis, a maioria dos locais pesquisados $(85,7 \%)$ oferta um quantitativo de até 25 vagas. Observamos em estudos realizados em Recife-PE e Campinas-SP, que a maioria das instituições apresenta um número de vagas similar, em torno de $30 .^{7-14}$

A dependência física aumenta com a idade, mas isso não deve pressupor incapacidade. É necessário reconhecer que o idoso pode ser dependente de cuidados de terceiros, mas independente para tomar decisões, portanto tem direito de exercer sua autonomia. ${ }^{2}$ No grau de dependência I, os idosos são independentes para as atividades de vida diária - vestir-se, higienizarse, alimentar-se; no entanto, utilizam algum instrumento para locomoção ou apoio; o grau de dependência II é responsável pelo comprometimento de até três atividades da vida diária do idoso; já o grau de dependência III está relacionado ao comprometimento de todas as atividades da vida diária e/ou atividades cognitivas. Neste estudo, verificou-se que $38,4 \%$ dos avaliados eram independentes para as atividades de vida diária; dados ligeiramente inferiores foram encontrados em Taubaté-SP num estudo realizado em 2001 e repetido em 2003, no qual 37\% dos idosos institucionalizados eram independentes. ${ }^{13}$

É relevante chamar atenção para a forma de seleção da instituição III, um dos requisitos para o ingresso na residência é a total independência, não comportando em sua estrutura social idosos com graus de dependência de nenhuma espécie.

A manutenção das ILPIs exige um alto investimento financeiro, são gastos com medicação, alimentação, higiene, adequação da estrutura física e cuidados ininterruptos. Nas instituições estudadas, constatamos que $57,1 \%$ são de natureza filantrópica, enquanto $28,5 \%$ são de natureza privada e apenas $14,3 \%$ são de natureza mista. Apesar de 100\% das ILPIs se apresentarem cadastradas no Conselho Municipal de Idosos de Olinda, apenas uma instituição recebe auxílio governamental, sendo este inferior a um salário mínimo mensal e liberado irregularmente durante o ano; $85,7 \%$ utilizam a aposentadoria dos residentes para sua manutenção na instituição, fato que condiz com resultados encontrados em Uberaba-SP, onde uma parcela mínima das ILPIs recebe verbas públicas. Esse achado está relacionado às dificuldades enfrentadas para o preenchimento e atendimento de todos os requisitos para o registro e manutenção oficial. ${ }^{15}$

Com um custo elevado e sem uma verba fixa, as instituições filantrópicas se mantêm através de doações particulares de roupas, móveis e cestas básicas, bem como contribuições das famílias, da própria aposentadoria dos idosos e de convênios com instituições religiosas. ${ }^{7}$ No caso das particulares, a procedência da renda é decorrente da aposentadoria, que mesmo sendo irrisória, é a única fonte de subsistência do idoso, permitindo o atendimento mínimo de suas necessidades básicas. Isso significa que a maioria paga sua estadia através do repasse de sua renda à instituição. $^{16}$

Pensar saúde transcende a visão de ausência de doenças. Nenhuma das correntes de pensamento, seja alopata, filosófica, antropológica, holística ou transdiciplinar, consegue dar uma definição 
completa do fenômeno saúde-doença. Acreditamos que a dificuldade em definir saúde esteja ligada ao fato de que saúde não é um fenômeno estático, que ocorre da mesma maneira para todos. Enquanto processo individual, tanto a saúde quanto a doença estão muito mais relacionadas à representação que cada sujeito tem do que seja saúde e doença. ${ }^{17}$

Como o envelhecimento é uma ocorrência normal que engloba todas as experiências de vida, o cuidado e as preocupações com os idosos não podem ser limitados a uma disciplina, porém são mais bem fornecidos através de um esforço de cooperação. Uma equipe interdisciplinar, através do histórico geriátrico abrangente, pode combinar a experiência e o recurso para fornecer as definições em todos os aspectos do processo de envelhecimento, fornecendo uma conduta holística para o cuidado. ${ }^{18}$

A carência de profissional administrativo capacitado para auxiliar no processo de gerenciamento agrava o problema de captação de recursos e qualidade da assistência prestada. ${ }^{15} \mathrm{Nem}$ sempre quem ocupa os cargos administrativos tem competência técnica para desempenhar suas atribuições - cargos por indicação e conveniência foram frequentemente encontrados.

A equipe funcional de recursos humanos e, consequentemente, os serviços prestados variam conforme as condições da instituição. Os cuidados de saúde são dispensados por cuidadores, auxiliares e técnicos de enfermagem, mas a supervisão de enfermagem está presente apenas em $42,8 \%$ das ILPIs. Serviços médicos, fisioterapia, psicologia e assistência social são oferecidos com pouca frequência e a nutrição está presente na maioria. Atividades físicas e outras complementares, como de recreação e lazer, cultura e religião, são oportunizadas em algumas das casas, conforme a estrutura e as condições.

Sobre essa questão, sobretudo em relação aos profissionais da equipe de enfermagem, nos deparamos frequentemente com instituições que não contam, em seu quadro, com as diversas categorias, mas voluntários que realizam procedimentos de competência do auxiliar, do técnico de enfermagem e até mesmo do enfermeiro. ${ }^{7}$ É preciso ter em mente que a assistência de enfermagem é prerrogativa legal apenas de profissionais devidamente habilitados. E quanto mais qualificada uma equipe de enfermagem, mais hábil ela é em traçar as estratégias de cuidado mais adequadas a cada paciente.

A Resolução COFEN-146, de 1992, estabelece em seu artigo $1^{\circ}$, que "toda instituição onde exista unidade de serviço que desenvolva ações de Enfermagem deverá ter enfermeiro durante todo o horário de funcionamento da unidade" ${ }^{19} \mathrm{De}$ acordo com pesquisa realizada por Pizarro (2004), as instituições geriátricas providas de profissionais de enfermagem legalizados foram as que menos apresentaram irregularidades no atendimento prestado ao idoso, colaborando para um bom envelhecimento. ${ }^{4}$

Com o avanço da idade, é preciso maior atenção aos fatores que possam interferir na manutenção da saúde da pessoa idosa, dentre os quais a qualidade nutricional. Uma dieta equilibrada junto a um cardápio variado construído pelo nutricionista é o ideal para que a transição do idoso de sua residência para a instituição de longa permanência aconteça de forma tranquila. ${ }^{20}$

Em todos os locais pesquisados, são feitas no mínimo seis refeições diárias e em 85,7\% o cardápio é construído por um nutricionista. No entanto, não há participação do idoso em sua elaboração, e sugestões devem ser tomadas quanto ao tempero, formas de preparo e a manipulação dos alimentos buscando a percepção e o respeito às características pessoais. ${ }^{20}$

Além disso, deve-se dar especial atenção à preparação do alimento: das sete instituições: observa-se que a maioria não dispõe de boas práticas para serviços de alimentação no que se refere ao transporte dos alimentos (interno e externo) e a distribuição dos mesmos. Um contingente alarmante $(85,7 \%)$ não possui normas e rotinas técnicas para o serviço de alimentação, 
incluindo limpeza, descontaminação, armazenagem, preparo e acondicionamento dos resíduos.

O cuidado com a saúde é importante em qualquer etapa da vida, mas se torna essencial em idade avançada, porque é nesta fase que as pessoas têm maior predisposição para desenvolver certos agravos, sobretudo as doenças crônicodegenerativas. ${ }^{17}$ Observamos a presença de diabetes mellitus e hipertensão arterial sistêmica como doenças de base mais frequentes. Os idosos das instituições pesquisadas apresentam bom estado geral: não foi constatado uso de sonda para alimentação, oxigenoterapia, ventilação mecânica, uso de sonda vesical ou coletor de urina e a presença de feridas crônicas, ou pessoas com diagnóstico ou tratamento para câncer, uma vez que as instituições fornecem assistência para as atividades de vida diária e atendimento básico de saúde, não tendo aporte material e humano necessário para demandas específicas.

A equipe, necessariamente multiprofissional, deve apoiar-se em atividades de cuidado, construindo um modelo em que resgate a dimensão da manutenção da capacidade funcional do idoso. A vigilância à saúde do idoso requer atenção e acompanhamento contínuos mediante práticas de saúde promocionais, preventivas e curativas, combinando os saberes profissionais específicos da geriatria/gerontologia e os populares do idoso institucionalizado. ${ }^{21}$

A participação social ativa inclui o movimento físico além do mental, como atividades de caminhada, ginástica e outras que ajudam na prevenção e promovem a saúde. Nas instituições geriátricas de longa permanência, é muito difícil encontrar e contemplar tais fatores: isso ocorre por ineficiência estrutural do local, ausência de pátios e jardins, e deficiência de profissionais, dentre outros. ${ }^{22}$ Das instituições analisadas, grande parte possui uma área externa para convivência e desenvolvimento de atividades ao ar livre, mas há uma pequena parcela de profissionais com formação de nível superior disponível para desenvolver tais atividades.

Quanto aos serviços que os idosos utilizam em caso de necessidade de atendimento imediato, constatou-se o uso do SUS - Pronto-Atendimento 24 horas - como o de maior destaque. Essa constatação aponta para as condições socioeconômicas dos institucionalizados, os quais dependem do encaminhamento das instituições que os abrigam. ${ }^{16}$ As situações de urgência são atendidas por equipes externas, e a remoção desses idosos é sempre feita por carros particulares e/ ou táxis, pois nenhuma instituição possui serviço de remoção especializado ou convênio com serviços terceirizados. Outros serviços que são solicitados em caso de necessidade integram o SAMU e os planos privados de saúde, porém esse último é a realidade de poucos idosos - apenas uma ILPI refere encaminhar $100 \%$ dos seus moradores à iniciativa privada.

\section{CONCLUSÃO}

Diante do crescente aumento da população idosa e levando-se em consideração que a institucionalização é por vezes a única alternativa para alguns idosos, é necessário que haja uma rede bem articulada de recursos humanos e estruturais para se atender da melhor maneira possível a essa população tão peculiar.

Com base nos resultados encontrados no presente estudo, pode-se concluir que nas instituições geriátricas de longa permanência para idosos de Olinda-PE há predominância de mulheres sobre homens; $38,4 \%$ possuem grau de dependência I; $33,1 \%$ apresentam grau de dependência II; e 28,5\% dos idosos apresentam um grau de dependência III. Todas as ILPIs (100\%) têm administrador; $57,1 \%$, serviço médico e de assistência social; $85,7 \%$, serviço de nutrição; $71,4 \%$ têm técnicos de enfermagem e $42,8 \%$ têm secretária, psicólogo e enfermeira. Quanto aos serviços que os idosos utilizam em caso de necessidade de atendimento imediato, constatouse o uso do SUS - Pronto-Atendimento 24 horas - em $57,1 \%$ das instituições pesquisadas.

No que diz respeito à situação do imóvel $71,4 \%$ das instituições visitadas são próprias. Em relação ao registro, $100 \%$ das instituições apresentam-se cadastradas no Conselho Municipal 
de Idosos, $57,1 \%$ são de natureza filantrópica, enquanto $28,6 \%$ são de natureza privada e $14,3 \%$ são de natureza mista. A aposentadoria dos idosos é utilizada em $71,4 \%$ dos casos. Em $85,7 \%$ das ILPI há alvará de funcionamento expedido pela Vigilância Sanitária e uma instituição (14,3\%) está em processo de regulamentação.

A realidade observada demonstrou urgência em ações voltadas à capacitação e adequação numérica dos recursos humanos para atender às peculiaridades desse grupo e proporcionar melhor qualidade de vida para esses sujeitos.

Identifica-se uma postura inerte do Estado frente às necessidades do idoso institucionalizado, como também a dimensão desta realidade como problema de saúde pública. Visto que a saúde é um direito de todos e dever do Estado, resguardar um ambiente de segurança e acolhimento da população idosa vem requerer uma postura pública que não se restrinja a execução e fiscalização de dispositivos legais que contemplem

\section{REFERÊNCIAS}

1. Universidade Federal de Minas Gerais (UFMG).Projeto lar dos idosos. Minas Gerais: [s.n.]; 2008. [ Acesso em ago 2008 ]Disponível em: < http:// www. medicina. ufmg.br/ laridosos /introdu. htm $>$.

2. Tier CG, Fontana RT, Soares NV. Refletindo sobre idosos institucionalizados. Rev Bras. Enferm 2004 maio/jun.; 57(3):332-5.

3. Ministério da Saúde(Brasil). Portaria n. 810, de 22 de setembro de 1989. Dispõe sobre normas para o funcionamento de casas de repouso, clínicas geriátricas e outras instituições destinadas ao atendimento de idosos. Diário Oficial da União 23 nov 1989.

4. Pizarro RAS. A importância da atuação do profissional enfermeiro na qualidade de vida dos idosos institucionalizados : uma avaliação qualitativa nas casas de repouso da Cidade de São Paulo. Santa Catarina. Dissertação [Mestrado em Enfermagem] - Universidade de Santa Catarina; 2004.

5. Santos SSC. Enfermagem geronto-geriátrica : da reflexão à ação cuidativa. João Pessoa: Editora Universitária/UFPB; 2000. esta parcela da população. Há uma desvalorização dos indivíduos idosos que já não compõem a força de trabalho. Esta ideologia é cultuada pela sociedade, que expõe o idoso a situações de insegurança e violência, como também a perda da autoestima, diante da exclusão do convívio familiar.

Uma discussão bastante polêmica emerge sobre a realidade de aposentadoria, considerada irrisória frente às necessidades específicas do ser humano idoso, que contribuiu com seu trabalho durante a maior parte de sua vida.

A realidade apresentada neste estudo tem o compromisso de alertar e mobilizar a sociedade acadêmica, profissionais de saúde, instituições representativas e de controle social, em trazer as questões referentes à cidadania do idoso institucionalizado para espaços consolidados de discussão das políticas de saúde que vislumbrem ações de promoção à saúde deste grupo etário tão desfavorecido do ponto de vista socioeconômico.
6. Martins RML. Envelhecimento e políticas sociais: viseu-Portugal. 2008 . [Acesso 12 ago 2008 ]. Disponível em: < www.ipv.pt/ millenium/Millenium32/10.pdf $>$.

7. Yamamoto A, Diogo MJD. Os idosos e as instituições asilares do município de Campinas. Rev Latino-Americana de Enfermagem 2002 set./out.; 10(5):660-6.

8. Ministério da Saúde(Brasil). Portaria n. 2528, de 19 de outubro de 2006. Dispõe sobre a política nacional de saúde da pessoa idosa. Diário oficial da união 20 out 2006.

9. Agência Nacional de Vigilância Sanitária( Brasil). Instrumento de avaliação para instituições de longa permanência para idososILPI. 2007 [Acesso em 07 mai 2007]Disponível em : < http://www.anvisa.gov.br/servicosaude/ organiza/instrumento_a $>$

10. Cervo AL, Bervian PA. Metodologia científica. 5. ed. São Paulo: Prentice/Hall do Brasil; 2002.

11. Ministério da Saúde(Brasil). Resolução n ${ }^{\circ}$. 196, de 15 out de 1996. Dispõe sobre as normas regulamentadoras de pesquisas envolvendo 
seres humanos. Brasília; Diário Oficial da União 16 out 1996.

12. Ribeiro MTF, et al. Perfil dos cuidadores de idosos nas instituições de longa permanência de Belo Horizonte.Ciênc saúde coletiva 2008; 13(4): 11285-1292.

13. Araújo MOPH, Ceolim MF. Avaliação do grau de independência de idosos residentes em instituições de longa permanência. Rev Escola de Enfermagem da USP 2007; 41(3):378-85.

14. Leal MCC, et al. Perfil de instituições asilares no município do Recife Brasil. Rev Bras Geriatria e Gerontologia 2006; 12(1): 39-48

15. Agreli GS ,et al. Idosos em instituições de longa permanência: condições de saúde, perfil sócioeconômico e voluntariado em Uberaba/ $\mathrm{Mg}$. [Acesso em 11 mai 2008].Disponível em: < www.saudebrasilnet.com.br/saude/trabalhos/ 076s.pdf>.

16. Herédia VBM, et al. A realidade do idoso institucionalizado. Textos sobre Envelhecimento 2004; 7(2).
17. Pestana CP, Espírito Santos FH. As engrenagens da saúde na terceira idade: um estudo com idosos asilados. Rev Esce Enferm USP 2008; 42(2):268-75.

18. Smeltezer SC, Bare BG. Brunner \& Suddarth: tratado de enfermagem medico cirúrgica. 10. ed. Rio de Janeiro: Guanabara koogan; 2005.

19. Conselho Federal de Enfermagem. A Resolução COFEN-146, de 1992. [Acesso em 21 out 2008 ].Disponível em: < (http:// www.portalcofen.gov.br/2007/ materias.asp? ArticleID $=7023 \&$ sectionID $=34)>$.

20. Santelle $\mathrm{O}$, et al. Alimentação institucionalizada e suas representações sociais entre moradores de instituições de longa permanência para idosos em São Paulol. Cad Saude Pública 2007 dez.; 23(12):3061-5.

21. Lenardt $\mathrm{MH}$, et al. $\mathrm{O}$ idoso institucionalizado e a cultura dos cuidadores profissionais. Congitare enfermagem 2006 mai/ago;11(2):117-23.

22. Ribeiro C. Idosos e família: asilo ou casa. 2008 [Acesso em 8 ago 2008]. Disponível em: < http://www.psicologia.com.pt > . 
